\title{
TRAINING OF PRACTICAL ENGINEERING SKILLS IN THE CONTEXT OF THE COVID-19 PANDEMIC
}

\author{
Petru Todos, ORCID: 0000-0003-2368-3871, \\ Petru Virlan *, ORCID: 0000-0002-7126-5191, \\ Ghenadie Tertea, ORCID: 0000-0002-5410-8901 \\ Technical University of Moldova, 168 Stefan cel Mare Blvd., Chisinau, Republic of Moldova \\ ${ }^{*}$ Corresponding author: Virlan Petru, petru.virlan@ie.utm.md
}

Received: 05. 24. 2021

Accepted: 07. 12. 2021

\begin{abstract}
This paper proposes a solution for carrying out laboratory work in the strict conditions of the Covid - 19 pandemic. The traditional laboratory can be replaced by the virtual laboratory or the remote laboratory, depending on the requirements of the course and the skills required for the training of engineers. The environment for performing alternative laboratory work (Virtual or Remote Laboratory) is the Multisim software from National Instruments. The student with the help of this software can make the electrical circuits provided in the curriculum of the discipline of General Electrical Engineering. This paper presents four examples of alternative laboratory works for the field of electrical engineering, namely, three-phase electrical circuits, static electrical converters, asynchronous motor and electric drive system. The student can simulate the required regimes in the laboratory guide and is free to simulate other regimes at his own initiative. The paper ends with the proposal of a step-by-step algorithm, which can be a guide for any teacher who wants to organize alternative laboratory work.
\end{abstract}

Keywords: traditional laboratory, virtual laboratory, NI multisim, engineers, electrical circuits, practical skills.

Rezumat. În această lucrare se propune o soluție pentru efectuarea lucrărilor de laborator în condițiile stricte ale pandemiei Covid - 19. Laboratorul tradițional poate fi înlocuit de laboratorul virtual sau laboratorul la distanță, în funcție de cerințele cursului și de abilitățile necesare pentru formarea inginerilor. Mediul pentru efectuarea de lucrări alternative de laborator (Laborator virtual sau la distanță) este software Multisim de la National Instruments. Cu ajutorul acestui software studentul poate realiza circuitele electrice prevăzute în programa de învățământ a disciplinei de inginerie electrică generală. Această lucrare reprezintă patru exemple de lucrări alternative de laborator pentru domeniul ingineriei electrice, și anume, circuite electrice trifazate, convertoare electrice statice, motor asincron și sistem de acționare electrică. Studentul poate simula regimurile solicitate în ghidul de laborator și este liber să simuleze alte regimuri din proprie inițiativă. Lucrarea se încheie cu propunerea unui algoritm pas cu pas, care poate fi un ghid pentru orice profesor ce dorește să efectueze lucrări alternative de laborator.

Cuvinte cheie: laborator tradițional, laborator virtual, NI multisim, ingineri, circuite electrice, abilități practice. 


\section{Introduction}

A laboratory is defined as a place where science is experienced. It can be said with confidence that laboratory investigations, developmentally appropriate, are essential for students of all ages and levels of education, they are an essential part of any science, especially in the training of engineers. The laboratory is a place where students not only perform experiments to understand different phenomena or complex processes, not only a place where they test the theory, but a place where they acquire practical skills (in measurements, analysis, optimization) permanently to improve and use them as a powerful factor in your future career as an engineer or scientific researcher. The paper addresses possible problems and solutions related to the practical / experimental training of engineering students, including in crisis situations such as pandemics.

\section{Changes are necessary}

The study programs for engineering specialties provide laboratory activities that constitute 20-30 percent of the total volume of study hours (e.g. curriculum of study programs in electrical energy and engineering electrical within TUM [1]). The real (physical) laboratory is well / much accepted by the students, here they see live the confirmation of the theoretical hypotheses related to the theoretical course. Learn to organize an experiment, how to make measurements and data analysis, to have important precautionary and safety skills, and to fulfill when operating with live electrical devices. But certain factors such as: the cost of laboratory facilities and maintenance costs, the need for systematic updating due to accelerated changes in the industry, emphasize the need to rethink the practical training of future engineers. The traditional laboratory limits to some extent the possibilities of organizing online studies especially for the field engineers [2].

The Covid - 19 pandemic crisis has further highlighted the seriousness of these problems. If you use the large scale of the Moodle platform and communication channels (Teams, Zoom, etc.) it allows, without great difficulties, the development / holding of lectures and seminars, it is much more problematic to carry out laboratory work. The demonstration of themed films, even of good quality, cannot substitute the didactic effect for the research activity, made by the student with physical equipment or with his model on the computer.

\section{Remote laboratory}

As an alternative to the real physical laboratory, the virtual laboratory with multiple variants of structure and mode of operation has appeared and is being developed. The concept of virtual laboratory was developed based on the evolution of ICT and is the main task to provide users with the necessary tools to perform remote experiments, as if a student were present in a traditional laboratory. The features of the virtual lab include global access and providing learning for geographically separated users. In addition, its functionality provides an easy-to-use environment for secure access to equipment, digital libraries, educational potential and tools for teamwork.

From the specialized literature [3 - 4] are known two types of laboratories in which the works take place / are carried out online: "remote" laboratories ("Remote Labs") and virtual ("Virtual lab").

The Virtual Lab is a web platform or software that offers any kind of experiment accessible online. This can be a remote controlled hardware lab or a total virtual lab [5].

A "remote controlled laboratory" in English. "Remote Labs" (also known as "cyber enabled lab") allows actors (students or employees) to perform experiments on the Internet, which 
are performed in real-time physical studies in educational or research laboratories. Compared to a conventional laboratory, in this case additional equipment is needed to prepare the traditional laboratory for: online access, measurements without support / human operator intervention, conversion of results to acceptable form for internet transmission to the client. Figure 1 schematically illustrates the operation of the remote laboratory.

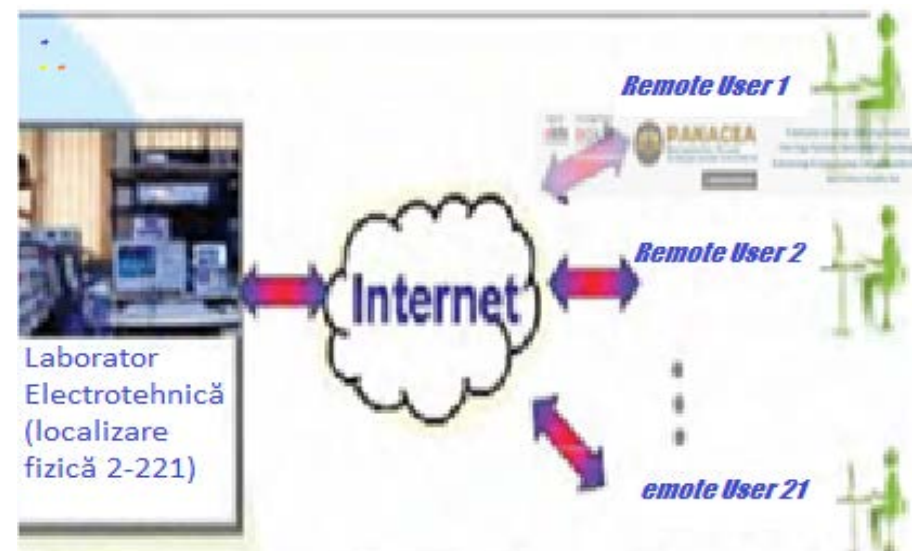

Figure 1. Remote laboratory architecture.

In a conventional laboratory environment, the actor uses the equipment with his own hands, obtaining direct feedback on any actions performed. When you press, for example, a button the actor will see what the "reaction" of the laboratory is, without any delay. In a remote lab, the actor is connected via a personal computer (or any other device, such as a smartphone or tablet) to the Internet. The actor is performing by using specific software or just by accessing a web application running in any common web browser. The user's actions are transmitted to a receiving system (in most cases a computer system) with a public IP address. Of course, this receiving system is preceded by a user / laboratory management system, which deals with access rights and booking issues. The receiver system is connected directly to the laboratory equipment, allowing the actor to perform the standard hardware actions that are possible for this specific type of experiment.

In a traditional laboratory, the work takes place according to a strict schedule and usually in groups of several people. Often there is no consideration for students with disabilities or for the individual time constraints of the participants. Another problem is the availability of sufficient laboratory stations. Due to the nature of the remote controlled laboratory, it is possible to share the equipment, not only between students from the home institution, but also between institutions (e.g. colleges or high schools). The access time can be extended with a convenient schedule for all categories of students.

\section{Virtual simulation laboratories}

The virtual simulation laboratory is created based on software. This software can be proprietary, but it can also be a simulated web service or hardware. Common to all virtual works is that real experiments are virtualized or simulated in this software. In most cases, it is an activity / problem close to reality. The virtual lab can be accessed like a real hardware lab. The user can perform the actions of the distance using a regular computer system, which provides input information through a network (involving the Internet) to a receiving system, in most cases directly related to virtual work. The system itself sends the feedback through the communication channel back to the actor's personal computer. All calculations are performed in the virtual lab and only this feedback is sent back to the user. Unlike the physical 
lab or Remote Labs, the virtual lab once configured can be used by many users simultaneously, being restricted only by the computing power of the host computer. It is more robust than the laboratory with real equipment, the student can not malfunction the virtualized hardware during adjustment and settings or programming errors. The system can also be duplicated at no additional cost.

Integrating virtual labs into a didactic management system is generally much easier than integrating remote hardware-based labs.

Remaining in the traditional laboratory paradigm, experiments in the virtual laboratory offer much more flexibility in selecting experience and introducing students to the new paradigm of distance experimentation [6 - 8]. This, in turn, allows the scope of experience to be extended. Thus, the platforms LabView, Matlab, Simulink, Multisim and others offer customers a rich arsenal of virtualized hardware components, models of machines / devices / electronic components and measuring devices from which users are invited to build their most diverse conversion systems. or command, to experiment without fear of failure, can organize tests for extreme situations, inadmissible for real physical hardware, thus gaining a negative experience of the consequences of exceeding the regulated limits.

Recent studies, based on student feedback, [7 - 9] show that work in virtual labs is well appreciated, fruitful, also improves users' digital skills, teaching them to work with communication tools. modern, developing their ability to solve complicated tasks in a digital environment, an important skill in training engineers in the context of the dizzying digitalization of today's and today's global industry [10].

Of course, virtual labs also have a disadvantage compared to conventional or remote ones. A virtual lab cannot perform experiments exactly like real hardware in all cases. The use of input data for the virtual laboratory experiment, derived from measurements on a real system or obtained by the student as a result of a research project, will greatly increase its interest and credibility, being closer to the "real world".

Often, in order to give the virtual laboratory a more realistic perception, various didactic procedures are used: the virtual model is dressed in a representative image of the machine / device; white windows with their valuable parameters and characteristics are used; the experiment is accompanied by clips with the car in action on a background specific sound; before or after the experiment, virtual visits are undertaken in a real laboratory. We agree with the authors' view [11] that the best solution would be a combination of virtual and remote labs to benefit from both.

\section{Virtual laboratory "At home"}

Being constrained by the pandemic situation that appeared in the spring of 2020, with the limitation of access to physical laboratories, we were put in a critical situation with the risk of deteriorating the process of practical training of future engineers. Creating remote labs is a long and expensive problem. The virtual lab is a much simpler option [13].

In the case of electrical engineering study programs, the research of phenomena, principles of operation and calculation / design are done based on mathematical models (systems of equations) and equivalent electrical schemes. These models are well proven and considered appropriate. They are well known on the largest modeling platforms Matlab, LabView, NI multisim that allow modeling the most diverse systems using an object-oriented language [14]. Based on a multilateral analysis, within the research project "Institutional and 
didactic digital transformations for distance engineering education in the Republic of Moldova, funded by the EU, it was concluded that for an extensive set of laboratory work in the fundamental and profile disciplines for the field of electrical engineering (electrical circuit, electronics, static and electromechanical converters, electrical and automated action systems) the most suitable is the NI multisim platform. The simplicity of the circuit capture, the rich arsenal of electrical and electromechanical components, its own measuring and analysis instruments and LabView make this platform very attractive [10]. In addition to this, we can mention the favored access for students [11], but also the wide use of this platform by professionals in the design, simulation and testing of electrical and electronic devices.

The assembly diagrams of the NI multisim models, as can be seen from the examples below, are presented with standardized symbols of the device used in the specialized technical documentation, as well as the theoretical courses. Behind them are mathematical models, which adequately describe the properties of those devices to an idealized extent. In order to obtain results as close as possible to reality, it is possible to operate with models of electrical and electronic components, proposed by the manufacturing company, models that are based on experimentally verified parameters and characteristics. NI multisim provides these materials. The results of the year projects or those calculated in practical lessons can also be used as input data. These are an important didactic effect [12].

Favored access for studies to the academic versions of the NI multisim platform allows the creation of a high-performance multidisciplinary virtual laboratory "at home". An extended tutorial plus the montage developed by the tutor, through a communication platform or internet, are made available to students enrolled in the course. These are downloaded to the personal computer version of the simulation platform. Freely or under the guidance of the teacher (on schedule), the student performs the planned experiments, completes the report which, through the communication platform (Moodle or Teams), will be sent for verification and grading.

We will present below some examples of laboratory papers tested during 2020/2021, developed for the field of studies in electrical engineering, but possibly adapted for other fields that study electrical engineering as a general discipline or electrical circuit, static electrical converters, converters electromechanical, electric drive and automation systems

Example 1. Three-phase electrical circuits. Based on the assembly in Figure 2, the student (semester 2 or 3) will experimentally examine the relationships between currents and line and phase voltages when connecting the star load; it is believed that the current in the neutral wire is zero if the load is symmetrical. The consequences of phase asymmetry in and without a neutral wire system will also be examined. In this series of student experiences you will learn and use the method of measuring power and power factor in three-phase circuits using only two watts. The student may be asked to modify the assembly and perform the necessary measurements for a delta connection load. In this package of works are studied: single-phase linear circuit - experimental verification of Ohm's and Kirchhoff's laws; resonance effects of voltages and currents, power factor compensation, asymmetry effects in three-phase circuits; methods and instruments for measuring power and other electrical quantities. 


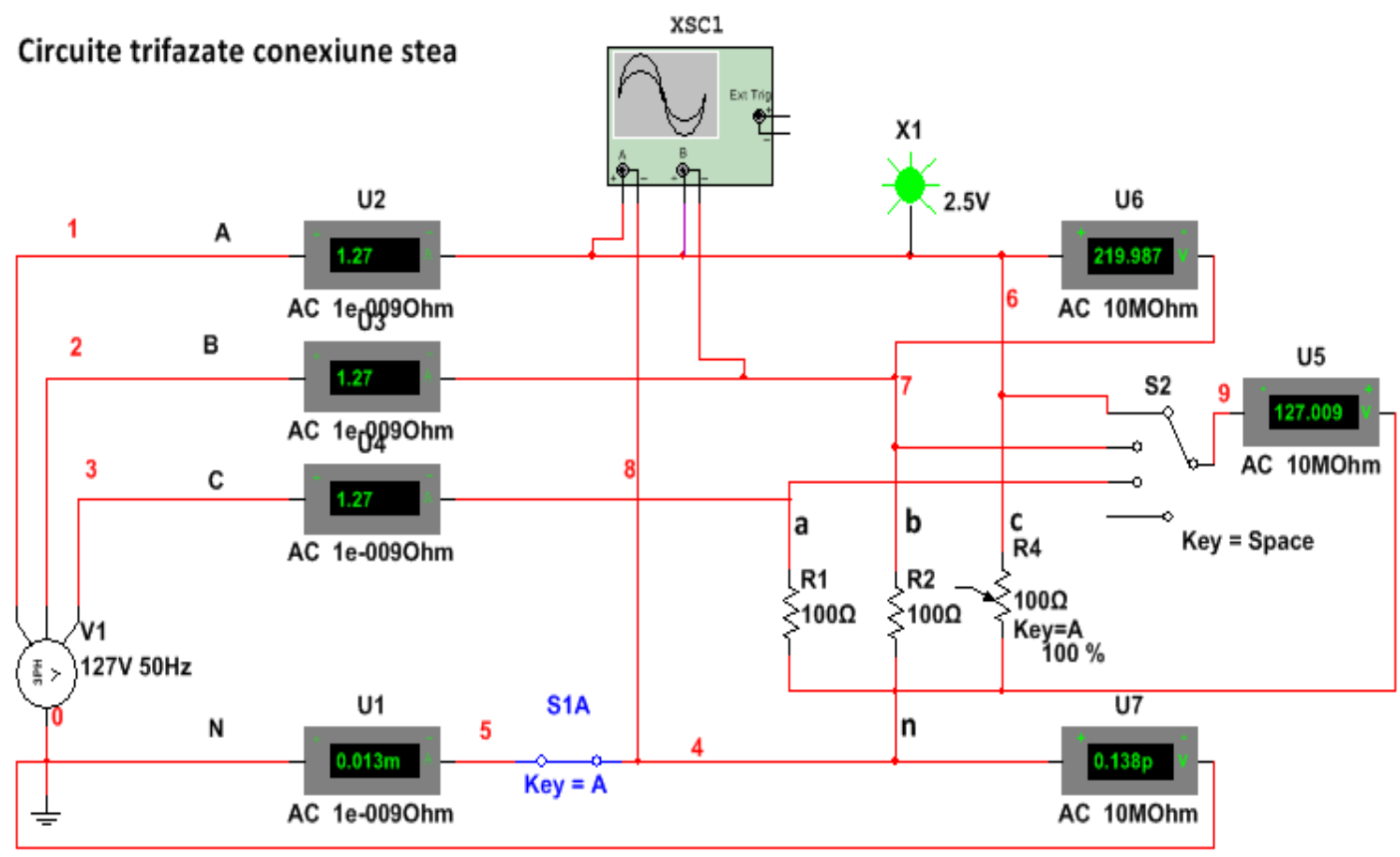

Figure 2. Multisim assembly for the study of three-phase electrical circuits, star connection.

Example 2. Static electrical converters.

For the students from the Electromechanical Systems Engineering program, the electronics course is fundamental, being that they are power electronic components, they are indispensable parts of any high-performance electromechanical system. Electronic devices used for the conversion of the basic parameters of electricity here are done with the help of controlled and uncontrolled rectifiers, inverters, DC or AC voltage variators. Electronic elements can also be components of the contactless switching system in the power circuits of motors, electric generators and other technological installations.

In this chapter we study in the form of models in multisim environment the most important for the specialty, electronic power devices, namely: single-alternator rectifier, three-phase thyristor bridge rectifier, chopper, AC inverter and inverter in the base of power transistors. The characteristics of some electronic components are also studied.

Experimental research is focused on the study of operating principles and methods of raising the characteristics that define the functionality of the electronic device as components in an electromechanical system: conversion characteristic, regulation characteristic, performance characteristic - efficiency, harmonic spectrum of current / output voltage. Here students will master the use of the two- and four-channel oscilloscope, the harmonic analyzer, other measuring and signal analysis devices. Figure 3 shows the multisim simulation assembly on a single-phase single-phase rectifier and example of captured oscillograms.

Example 3. In the electrical machine compartment the standard procedures for experimental determination of the parameters of a single-phase transformer are simulated, the process of determining the time group for three-phase transformers with various connection schemes to primary and secondary, the study of transient processes and raising the characteristics of operates in stabilized mode of DC motors and an asynchronous motor with short-circuited rotor MARSC. 


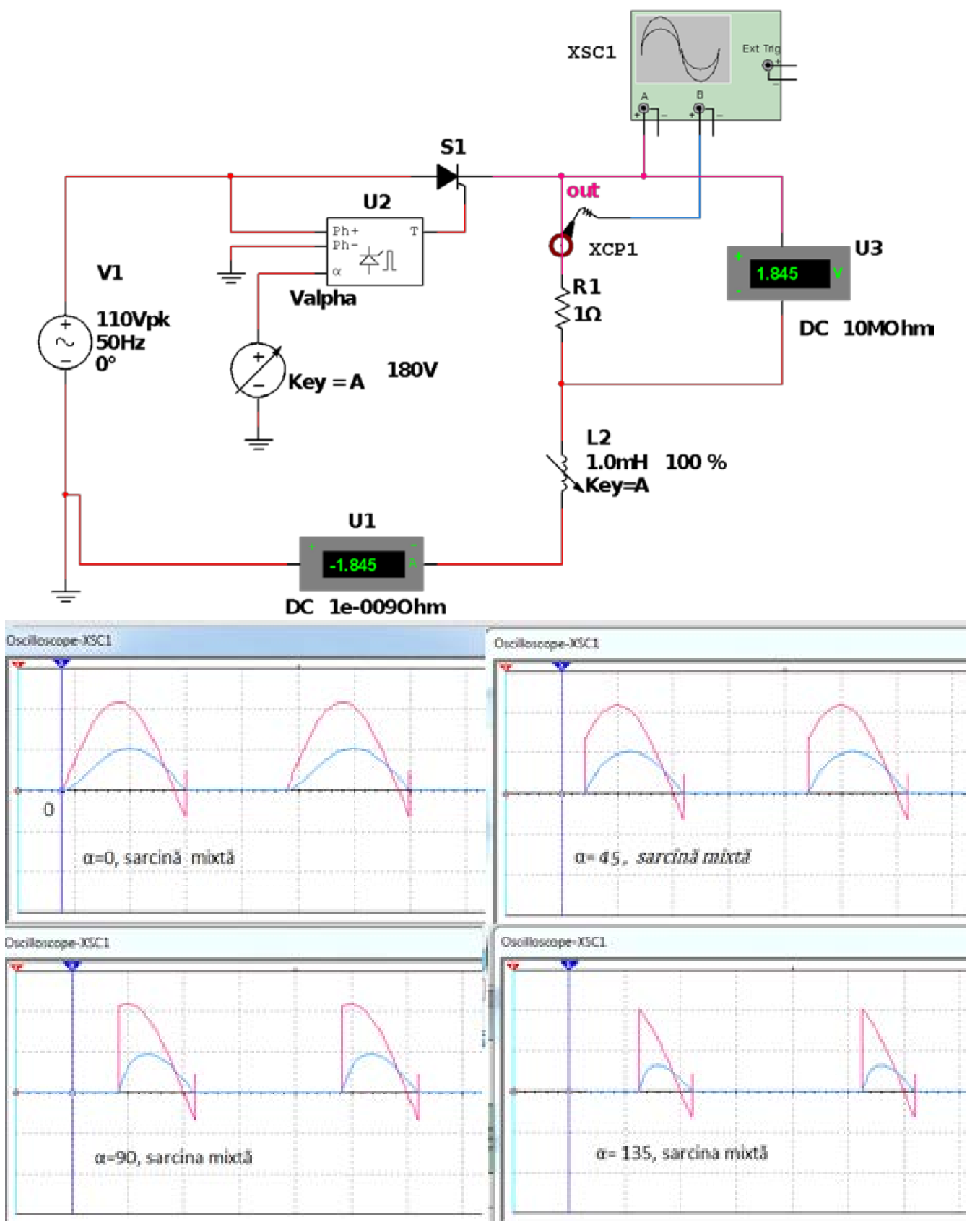

Figure 3. Simulation of the mono alternator rectifier with thyristor, example of oscillograms.

Figure 4 shows the assembly used to study the operating characteristics of MARSC, which allows recording diagrams for stator feed current, torque and angular velocity of the shaft at direct start of engine idling and under load. By adjusting task information, students can experimentally raise the operating characteristics of the engine: torque, active power consumed, efficiency and slip according to shaft power, also determine key coordinates of mechanical and electromechanical characteristics, thus mimicking the activities of an engineer in the laboratory testing of electric machines. The assembly, by adjusting the voltage frequency to the power supply, allows to demonstrate the possible adjustment of the motor speed by frequency. We consider that for students it would be very attractive if the parameters of an engine designed by them, within the same course, were used to adjust the engine simulation model. The assembly can also be used for the experimental optimization of the parameters of this designed engine. 


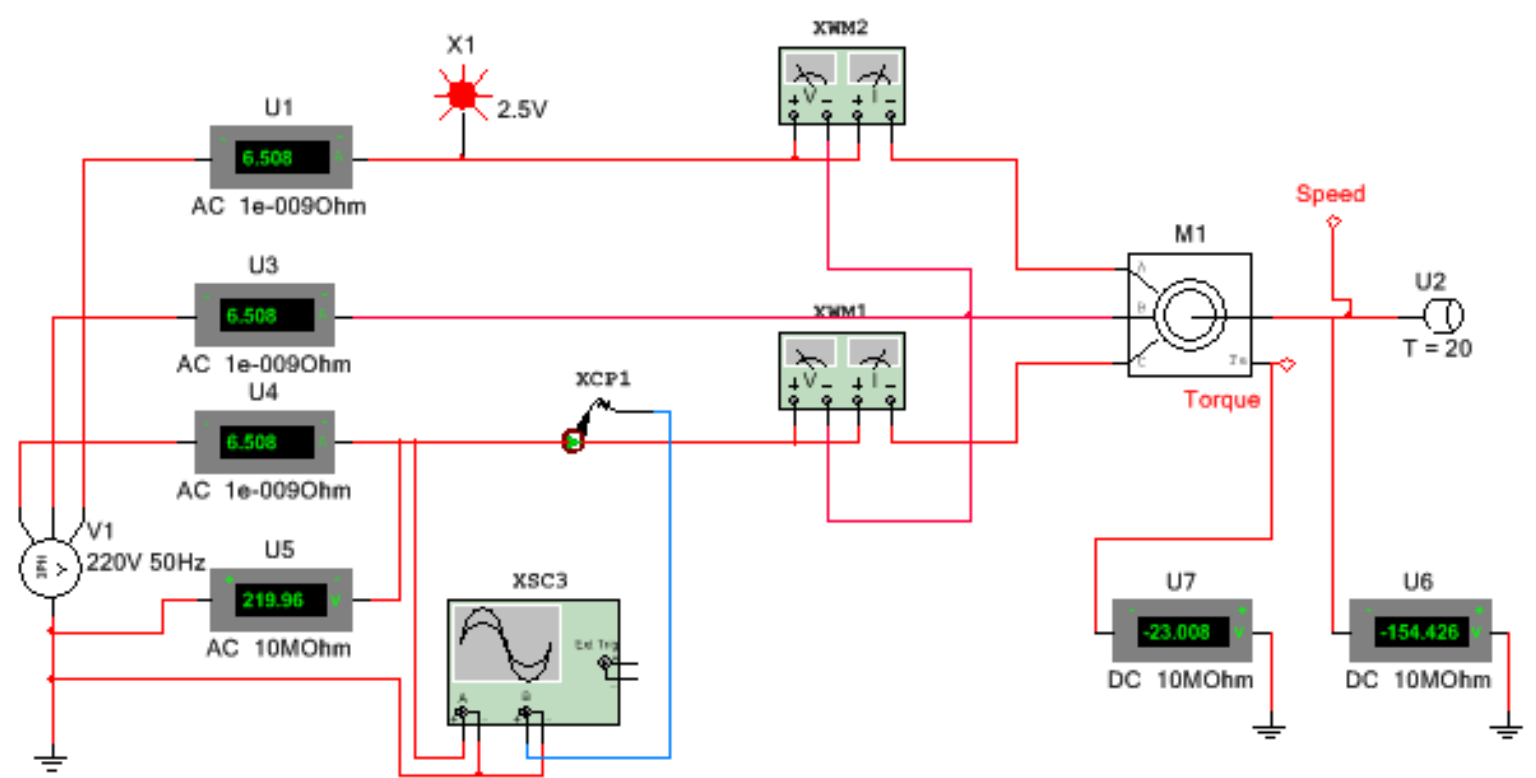

Figure 4. Study of the transient and stationary characteristics of MARSC.

Example 4. An electric drive system with asynchronous motor and closed loop frequency converter with different load variants; electric drive of a stepper robot arm; traction system for electric vehicles with brushless DC motor (BLDC); vector control synchronous motor drive system is the set of works in the discipline Typical electrical drives, performed by students in the final year of the bachelor's cycle. Figure 5 shows the multisim assembly of the BLDC motor system with the power supply converter and the respective control system and several examples of diagrams on the static and dynamic processes investigated.

How to organize, operate and communicate. Required software and hardware

The Moodle educational platform is used at TMU for online communication with asynchronous studies [10]. At each course registered on the platform are placed materials on the theoretical content, presents PPT, electronic resources, individual tasks, self-assessment tests, current and final assessment. Synchronous communication, online, is done primarily in the Teams environment.

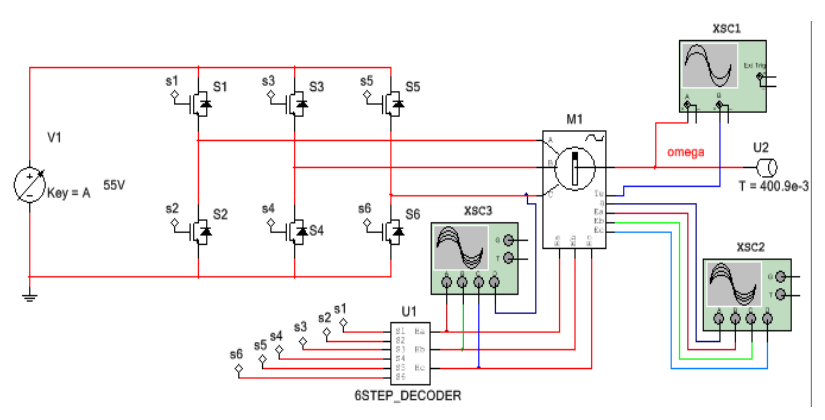

a)

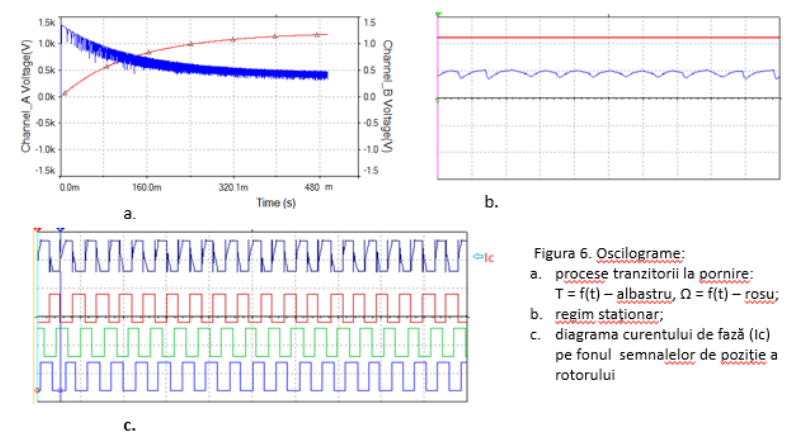

b)

Figure 5. Actuation system with brushless DC motor: a) Multisim scheme; b) Extracted diagrams.

The following working algorithm was proposed for the organization of laboratory works.

Step 1 The holder places on the Moodle platform as a resource the respective chapters of the course of the laboratory work tutorial with the description of the purpose, the research program, the methodical indications regarding the realization of the program and the 
processing of the measurement results and other observations made. Also here, as a separate document, is placed the assembly of the $\mathrm{NI}$ multisim simulation model of the equipment or system to be researched.

Step 2. In the scheduled hours, the teacher, operating in the Teams environment, questions studies on the knowledge of the tasks to be performed, explains the unclear questions, then from his computer demonstrates the most difficult operations to adjust equipment parameters and other date of entry, execution of experiments.

Step 3. Students transport the simulation model assembly from the Moodle platform to the desktop of the personal computer. An updated version of NI multisim is installed on your computer.

Step 4. The student executes the prescribed program with the personalized entry date. Tutors can intervene with checks or consultations. For this it is enough for the student to share the screen with the respective teacher.

Step 5. The student works independently on the improvement of the reports, using the results obtained by measurements, observations made with the help of the oscilloscope and analysis devices, included in the scheme of the simulation model.

Step 6. The student can return to the paper at any time, can repeat in full or even experiments from the paper. Research experiments outside the program are not prohibited.

Step 7. The completed report is placed on the Moodle platform, in the place indicated on the course page, for verification and grading.

The student must have downloaded to his personal computer (PC, notebook, tablet, high-performance mobile phone) an updated version of $\mathrm{NI}$ multisim. Once downloaded this software will be used for the entire period of study and after, if needed.

Thus, we propose an easy-to-make laboratory variant, which does not increase equipment and maintenance costs. Only software and platforms with free access for education are used. Multisim is studied on the go, in the laboratory activities at the respective courses.

\section{Conclusions}

1. The need for laboratory work that can be performed remotely, imposed crisis pandemic, economic conditions and the trend in development to do more research the online

2. Remote laboratories and virtual presents a real opportunity and perspective for the professional competence form of the engineering program.

3. It has been practically demonstrated that the Internet and the current IT and communication platform allow the development of the virtual multidisciplinary laboratory at home with the simulation of the static and dynamic processes of the most complex equipment and systems and ample research possibilities.

\section{Bibliography}

1. Adăscăliței Adrian. Teoria circuitelor electrice: indrumar de laborator / Adrian Adăscăliţei. - Iaşi : Performantica, 2015 Bibliogr.ISBN 978-606-685-303-3

2. Joshua Grodotzki, Tobias R.Ortelt, A. ErmanTekkaya. Remote and virtual labs for Engineering Education 4.0. The 46th North American SME Industry Research Conference, NAMRC 46, Texas, USA. Published in Procedia Manufacturing 26 (2018) 1349 - 1360

3. S. Seiler. Current trends in Remote and Virtual EngineeringLab. PAPER 276538416, Bochum, Germany. http://dx.doi.org/10.3991/ijoe.v9i6.2898 
4. A Virtual Future for the Control Laboratory, bySimon Whitmell - Engineering curriculum specialist Quanser, sept. 22, 2020.

5. Vladislav Slavov, Asya Asenova, Kameliya Yotovska. Virtual laboratories to increase digital skills in the field of education engineering. March 2019. DOI: 10.21125 / inted.2019.2415

6. Hristoph J. Paulus, Nazim Haouchine, David Cazier, Stephane Cotin. Augmented reality during cutting and tearing deformable objects. In: IEEE 2015 International Symposium on Mixed and Augmented Reality. September 29, 2015. DOI:10.1109 / ISMAR.2015.19

7. Ghencea Cristina, Todos Petru, Virlan Petru. The quality of online courses in the students perception. În Proceedings of the 11-th International Conference on Electromechanical and Power Systems SIELMEN 2017, 11 - 13 october 2017, lasi - Chișinău, 358 - 363p. Catalog IEEE: CEP17L58-USB, ISBN 978-1-5386-1845.

8. Vîrlan Petru, Todos Petru, Nucă Ilie. Technology for the implementation remote laboratories. In materialele celei de a XIX conferință Națională de Acționări Electrice. TUlași, 7 - 8 iunie 2018. Buletinul Institutului Politehnic din Iaşi, publicat de Universitatea Tehnica " Gheorghe Asachi" din lasi, C146, 2018. ISSN 1223 - 8139, Online ISSN 2537-2726 (clasificator B+).

9. Virtual laboratories: an investigation into the future of teaching laboratories. https://blog.bham.ac.uk/itinnovation/2018/05/17/virtual-labs-an-investigation-in-to-the-future-of-theteaching-labs/

10.UTM FEIE, curriculum https://feie.utm.md/studies/

11. NI Multisim User Manual - National Instruments. https://www.ni.com ıpdf t textbooks

12.https://www.ni.com/en-us/support/downloads/software-products/download.multisim.html\#312060

13. S. Seiler. Definition of remote, online, virtual, simulation and remote. http://seiler.it/remote-and-virtual-labs/

14. Educational platform Moodle UTM. http://moodle.utm.md 